OnLine Journal of Biological Sciences 11 (2): 76-83, 2011

ISSN 1608-4217

(C) 2011 Nedosa and Anastasia et al., This open access article is distributed under a Creative Commons Attribution (CC-BY) 3.0 license

\title{
Cell Surface Receptor Theory of Disease Infectivity; Body's Defence and Normal Body Functioning in Living Things
}

\author{
Utoh-Nedosa and Uchechukwu Anastasia \\ Department of Pharmacology and Toxicology, \\ Faculty of Pharmaceutical Sciences, \\ Nnamdi Azikiwe University, Awka, Anambra State, Nigeria
}

\begin{abstract}
Problem statement: A study of the pattern of Candida spp. infection of the human body and the mode and pattern of reaction of the human body to this infection showed that disease infectivity and self healing by plants followed the same procedures and patterns. Approach: A comparism of these procedures and patterns of natural self- healing of disease infection by the human body and plants/plant parts with the cutaneous Candida spp. killing and elimination procedures and patterns of Vernonia amygdalina leaf extract, showed that cell surface receptors are the sites through which disease infects the body and also the sites at which the body is defended. They are also the sites where activities which result in normal body functioning are carried out. The mode and patterns of Cutaneous Candida infection in a human subject and its containment by the body was examined and photographed. The disease infection and self healing procedures and patterns of plants were also examined in comparism with those of their healthy counterparts and photographed. The findings from the observations on disease infectivity and natural body's defence patterns and procedures of the plant parts studied and those of the human body in reaction to Candida spp. infection were compared with those of the Candida spp. killing procedures and patterns of aqueous and Arachis hypogeal oil extract of Vernonia amygdalina leaf. Results: The findings of this study also showed that disease-infective organisms gain access to the body of a host through attachment to the cell surface receptors of that host which are placed linearly and are interconnected by channels. The results of the study also indicated that living organisms have a main endogenous substance that mediates both their body's defence and their normal physiological functioning which is therefore the owner of the cell surface receptor. Other endogenous substances which participate in normal body functioning/body's defence or in body's offence like hormones, drugs, toxins and venoms interact with the body through the cell surface receptors (which are the receptors of the main mediator of the body's defence and normal functioning of an organism. Substances like lidocaine (an anesthetic); tetrodotoxin and afflatoxin therefore inhibit or antagonize the normal functioning of the body by blocking the excitatory actions of the mediator of normal body functioning. Conclusion: The study concludes that cell surface receptors are the sites through which infective organisms attach to the body of a host and that the cell surface receptor has two reactive terminals or heads with which endogenous and exogenous substances like drugs and infective pathogens interact with the body of a living organism.
\end{abstract}

Key words: Vernonia amygdalina leaf, physiological functioning, normal functioning, infective pathogens, exogenous substances, body's defence, cell surface receptor, disease infectivity

\section{INTRODUCTION}

Many people all over the world today are interested JN obtaining information on the antimicrobial and body protective activities of natural food substances, herbal extracts and food supplements. This study was an examination of the patterns of Candida spp. Killing and elimination effects of Vernonia amygdalina leaf extract because Candida spp. have proved difficult to eliminate by currently available antifungal drugs (Siamba et al., 2007). The mechanisms by which plants are infected by diseases and the mechanisms by which plants treat themselves of their infections were also studied for comparative purposes.

Corresponding Author: Utoh-Nedosa, Department of Pharmacology and Toxicology, Faculty of Pharmaceutical Sciences, Nnamdi Azikiwe University, Awka, Anambra State, Nigeria 


\section{MATERIALS AND METHODS}

The study consisted of the collection of specimens of various similar healthy and infected plant parts and their examination with the unaided eye to note the presence or absence of disease on the outer covering of the plant parts. The cutaneous Candida infected sites of a human subject was similarly examined.

The mode of data collection was the observation of the mode and patterns of disease infection and self healing by plants and photographing of these observations. The mode and patterns of cutaneous Candida spp. infection and its natural healing by the human body were observed and photographed in a human subject. The findings from the observations on disease infectivity and body's defence patterns and procedures of the plants and those of the human body in reaction to Candida spp. infection were compared with those of the Candida spp. Killing effects of Vernonia amygdalina aqueous and Arachis hypogeal oil extracts.

The effects of oral and topical applications of $V$. amygdalina leaf extract were examined.

The aqueous leaf extract was prepared by hot water infusion of $V$. amygdalina leaves while the topical application consisted of the aqueous and arachis hypogeal extracts of the $V$. amygdalina leaf powder.

An Infusion of fragments of dried wholesome mature red stalked $V$. amygdalina (bitter leaf) leaves was made by putting them in twice their own volume of boiling drinking water in a clean cooking pot. Stirring of the leaf fragments for 10-15 min enhanced complete effusion of the $V$. amygdalina leaf extract into the boiling water.

Red stalked spindle shaped Vernonia amygdalina leaves which were dried in low sunshine and ground into very fine powder with a grinding mill. Ingestion of the $V$. amygdalina powder with the finely ground fibers mimicked the eating of the bitter leaf soup 9liquid) and the bitter leaf fibers together in the bitter leaf soup.

The $V$. amygdalina oil extract was made by dissolving $10 \mathrm{~g}$ of the $V$. amygdalina leaf powder in $50 \mathrm{~mL}$ of pure Arachis hypogeal oil.

The subject was banned from excess calorie intake during the treatment which was achieved by not taking high lipid and carbohydrate foods like the following foods: lard, vegetable oil, butter/margarine; mayonnaise; grated coconut; bacon; ground nut/peanut butter; nuts like palm nut, coconut, date palm; oil fried foods; oily seeds like beniseed, egusi, sun flower seed; oily fruits like avocado pea, Nigerian pea; oily soups, stews or gravies; oily cooked or prepared meals like salads, bean cakes and from pastries or flour foods like dough nuts, burns, cakes, spaghetti/macaroni, bread. Consumption of alcohol/alcoholic drinks; acid based beverages like tea, cocoa and coffee; acid fruit juices like lemon juice; soft drinks (including malt drinks and carbonated drinks); tobacco or tobacco products; garlic and acidic food spices and condiments; artificial food seasoning (artificial salt or salt substitutes including potash) was also banned for the subject during the treatment.

The subject's meals consisted of two daily meals which contained their normal daily requirements of proteins, non-acidic fruits; mineral salts and water. Only one third of the carbohydrates meals and one tenth of the fats and oils previously consumed by the subject were permitted to be eaten by eaten by the subject. Two thirds of the carbohydrates which the subject previously consumed were replaced by nonacidic leafy green vegetables.

The oral aqueous $V$. amygdalina extract was taken in $2 \times 33 \mathrm{~mL}$ cups four times daily. The oral $V$. amygdalina crude powder was taken in $10 \mathrm{~g}$ doses taken with drinking water of room temperature four times daily.

The same aqueous $V$. amygdalina leaf extract which was used for oral treatment was also applied topically on the cutaneous Candida infection. The Arachis hypogeal extract of $V$. amygdalina leaf powder was also applied topically on the cutaneous Candida infected sites.

\section{RESULTS}

The results of the study showed that oral and topical applications of Vernonia amygdalina leaf extract and powder have systemic and cutaneous Candida species killing and elimination effects.

These Candida sp. killing effects of $V$. amygdalina aqueous and oil leaf extract occurred in $1 \mathrm{sec}$ to $2 \mathrm{~min}$. The effects were dose/concentration dependent and could last $12-17 \mathrm{~h}$ in heavily infect

High concentrations of oral or topical $V$. amygdalina leaf extract simply burnt out the centromere and hyphae of the Candida specie in a locality without leaving any trace of their former site of residence in the host. This total per oxidation and catabolism of the tissues of a Candida spp. Colony in a locality occurred in a fraction of a second in a linear fashion that resembled the burning of an electric cable which is on fire. Such eliminations of a Candida colony usually started from one location of the colony where the $V$. amygdalina extract first encountered the Candida tissues, to the end of the last Candida hyphae in that Candida colony.

The Candida sp. killing actions of low but efficacious concentrations of oral or topically applied $V$. amygdalina leaf extract involved a low-keyed stinging or gentle per oxidation ('blebing') of the candida sp. 
centromeres (the usually circular root or attachment of the Candida colony) and hyphae which caused the Candida tissues to be raised up with a red flare (a red rash) an action which was not usually felt by the subject.

The Candida species killing and elimination effects of $V$. amygdalina leaf extract were found to be dose, concentration, frequency and time dependent.

Candida-infected cutaneous sites which were flared-up were burnt out by the next time efficacious concentrations of the $V$. amygdalina leaf extract (which initially caused a red flaring and edematous enlargement of the Candida sp. tissues) was taken by the subject (Fig. 2a-d). With such low but efficacious doses of $V$. amygdalina leaf extract, continual use of the same dose produced an additive effect which later wiped away (burnt off) the already inflamed embedded tissues of the Candida sp. colony.

Some lulled but continuous pain and mild stinging actions of the $V$. amygdalina extract was felt at systemic infected sites in the body during the period of the pharmacologic actions of the $V$. amygdalina leaf extract in the body.

Efficacious systemic Candidacidal actions of the $V$. amygdalina leaf extract were marked by dull but distressing monotonouspre-treatment pain at such systemic infected sites (as the body's warning sign of the presence of such an infection). Activity of the $V$. amygdalina extract at such systemic sights was marked by fragmented but continuous mild stings or itching with the release of heat at the site during the phase of the actions of the extract on the Candida infections. An experience of peace and quiet at such formerly infected systemic site indicated successful wiping out of the infection at that site or an elimination of most of the Candida colonies at that systemic site by the $V$. amygdalina treatment regimen.

Candidacidal actions of oral $V$. amygdalina extract at heavily infected cutaneous sites were marked by prolonged continuous blebing actions at that site for $12-17 \mathrm{~h}$.

The blebbing action of topically deposited $V$. amygdalina powder on lingual Candida infection was accompanied by the escape and bubling of gas which is likely to be carbon dioxide from the per oxidized Candida tissues. The consummation action of topically applied $V$. amygdalina leaf extract could be observed with the naked eyes as like the sweeping clean of a formally dirty place in $1 \mathrm{sec}$ to $2 \mathrm{~min}$ from the site of application of the extract to parts of the body beyond the site of application.
The examination and comparism of healthy and infected animals and plants including the reaction of the human body to cutaneous Candida infection showed that:

- The human body and the body of all living things contain numerous cell surface receptors to which disease infective organisms attach to attack and destroy the body (Fig. 1-5)

- These cell surface receptors are arranged in straight lines and are interconnected to one another through channels which the author has given the name receptor channels. These receptor channels criss-cross one another and are very visible in Fig. 1a and b; 2b-e and g; 3a-d; 4a-f and in Fig. 5a and b

- The disease infection seen on the orange fruit (Fig. $3 \mathrm{a}-\mathrm{d}$, on the human cutaneous infection and its treatment Fig. 1a and $\mathrm{b}$ and $2 \mathrm{a}-\mathrm{g}$; on the mango fruit Fig. 5a and on the pea fruits (Fig. 4a-f) showed that disease infective organisms attack and destroy the body through and the cell surface receptors and their channels. Disease infection starts and continues to progressively destroy cells surface receptors along their straight line channels of interconnections with other cell surface receptors until the whole tissue; organ; system or body is systematically destroyed

- The Candida spp. Treatment procedure and patterns by $V$. amygdalina extract in Fig. $1 \mathrm{a}$ and $\mathrm{b}$ and $2 \mathrm{a}-\mathrm{g}$ and the self treatment procedure/patterns of the mango fruit and the pea fruit showed that both the endogenous body defence substance and exogenous drugs start their destruction of the infective substance at the root of attachment of the infective organism at the cell surface receptor and proceed in straight lines along the receptor channels through which the infective organism spread until the arrest the infection or kill off all the infective organisms or their tissues

- $\quad$ Raised cell surface receptors (sometimes with red flare) are indicative of an infection being attacked by an endogenous body defence substance as shown in Fig. 1b or an exogenous drug as in examples in Fig. 2

- The glossy substance poured onto the infected cell surface receptors on the mango fruits show the existence of endogenous body defence/normal body functioning maintainance substances in living things and the cell surface receptor as the receptor of this body defence substance 
OnLine J. Biol. Sci., 11 (2): 76-83, 2011

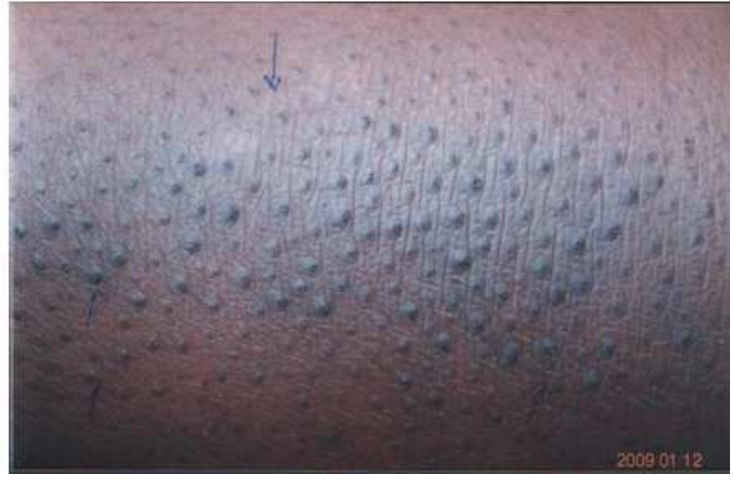

(a)

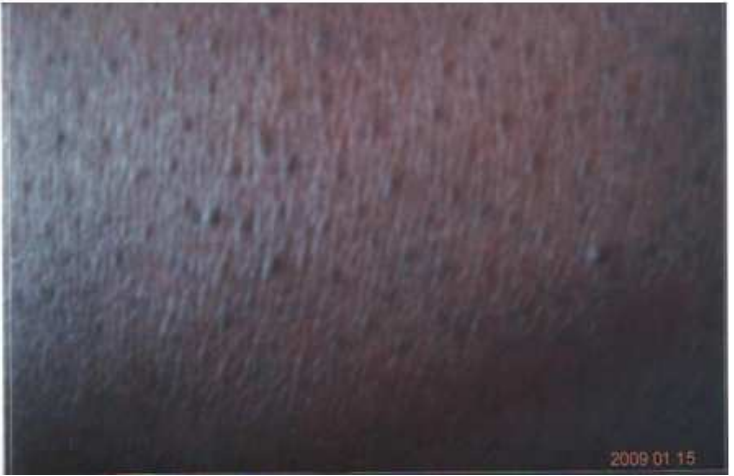

(b)

Fig. 1: The spots marked by arrows are cell surface receptors while the grooves marked by arrows are cell surface receptor channels

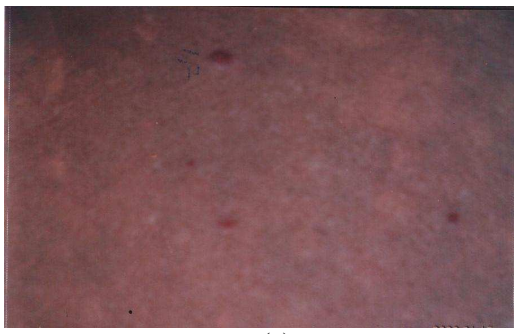

(a)

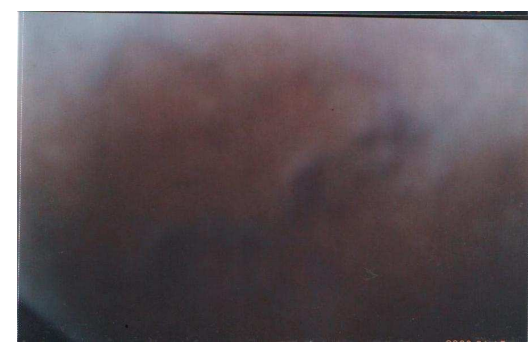

(d)

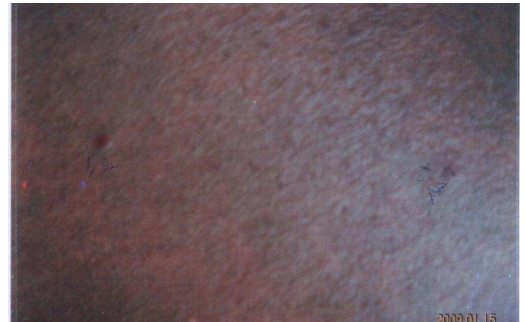

(b)

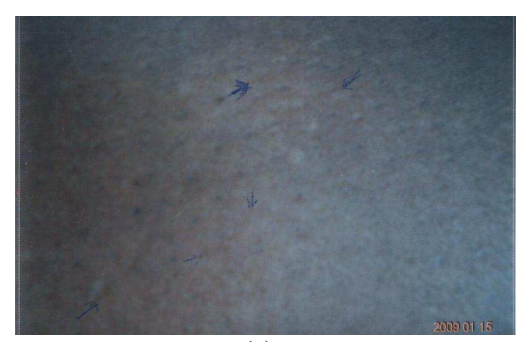

(e)

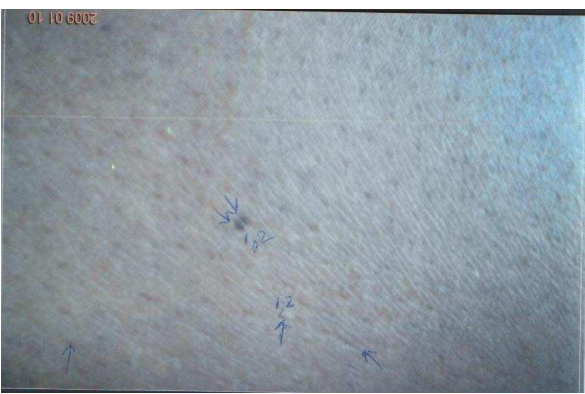

(g)

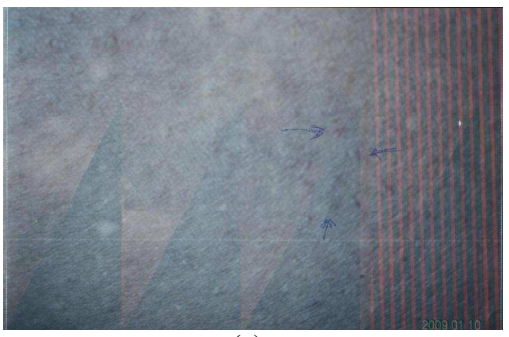

(c)

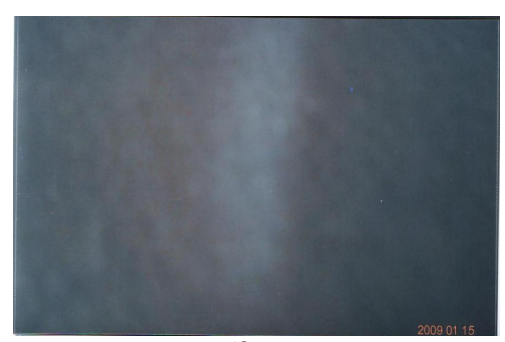

(f)

Fig. 2: The spots marked by arrows are cell surface receptors while the grooves marked by arrows are cell surface receptor channels 
OnLine J. Biol. Sci., 11 (2): 76-83, 2011

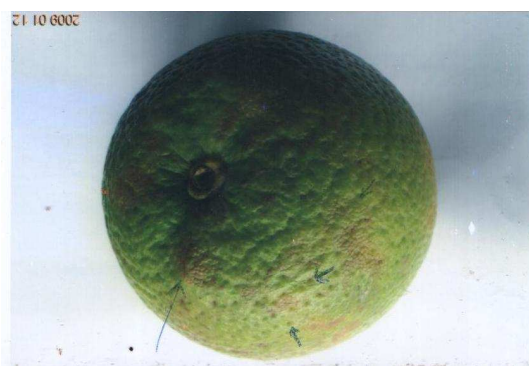

(a)

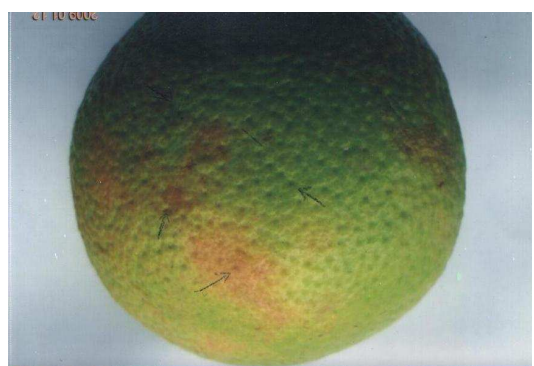

(b)

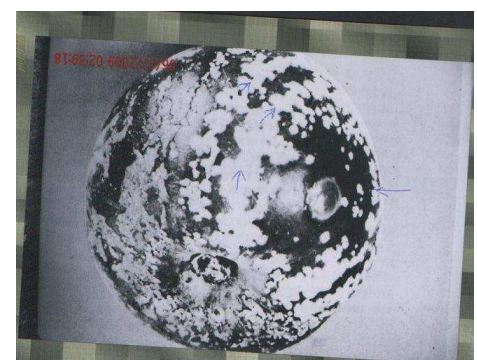

(c)

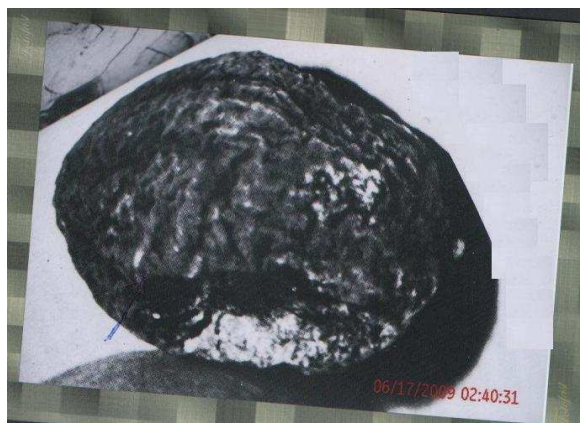

(d)

Fig. 3: The spots marked by arrows are cell surface receptors while the grooves marked by arrows are cell surface receptor channels

- The self treatment of the mango and especially the pear infection by the fruit even after it had been plucked demonstrated that there is a main endogenous mediator substance that defends the body against injury and infection; that that substance monitors the whole body indefinitely and attaches to infected cell surface receptors to uproot such infections

- The endogenous mediator of the body defence of an organism is therefore also the main mediator of normal physiological body functioning of that organism since it has to be permanently on guard of the body to ensure that the body is protected from disease infection, injury and death

- This study demonstrated that both the endogenous body difence substance and exogenous body defence substances like drugs first inflame or flare the tissues of the invading substance at the cell surface receptor attachment site of the infective organism and subsequently kill and eliminate the organism. Note that the red flare of the disease infection sites of the pear fruit in Fig. $4 \mathrm{~b}$ resembles the red flare of the cutaneous Candida tissues by Vernonia amygdalina leaf extract in Fig. 2a-d. Note also that that the human body defence mediator flared the roots of the Candida infection site in figure 1a than it flared the sites in Fig. 1b (the complementary side of the body) because the Fig. 1a site is a more heavily infected site

- The findings of the study also indicate cell surface receptor sites and cell surface receptor channels from which infective organisms had been cleared ( by a drug or an endogenous body defence substance are wider, deeper and more pronounced than intact ones (Fig. 2b-g) and (Fig. 4a-f). Note that disease damaged cell surface receptors sites and their channels are very deep which indicates that many of them had become destroyed by the disease (Fig. $3 \mathrm{~d})$

- The cell surface receptor sites highlighted by $V$. amygdalina treatment in the red flare of the receptor site and in the Candida cured sites Fig. 2ae and $\mathrm{g}$, demonstrated that the cell surface receptor site has two terminals or ends with which infective organisms, endogenous substances and exogenous substances interact to defend or offend the body. These two ends are marked 1 and 2 in the photographs

- The study also found that the owner of the cell surface receptor is the endogenous mediator of the body's defence and normal body functioning since this substance constantly sits on this receptor to protect the body from disease infection, injury and death 
OnLine J. Biol. Sci., 11 (2): 76-83, 2011

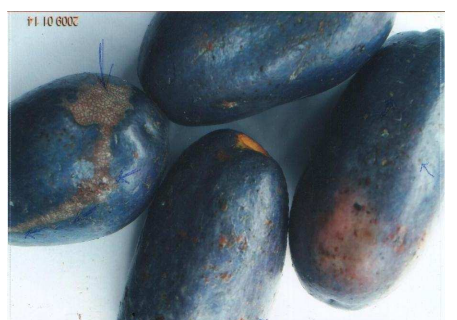

(a)

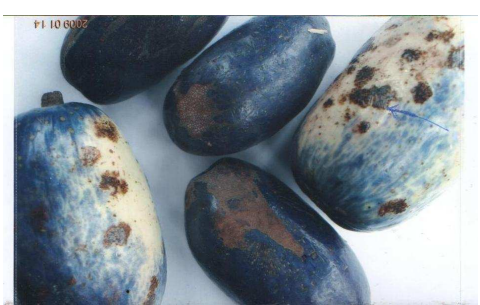

(d)

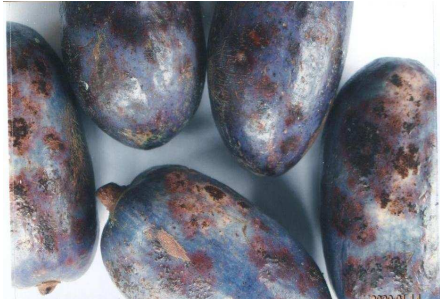

(b)

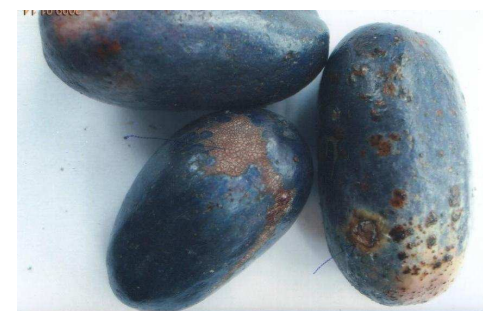

(e)

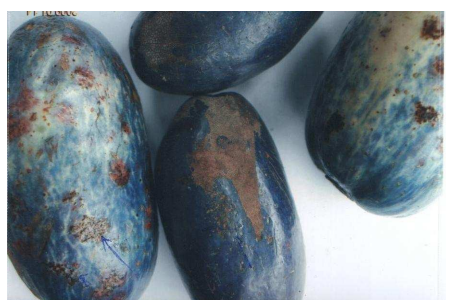

(c)

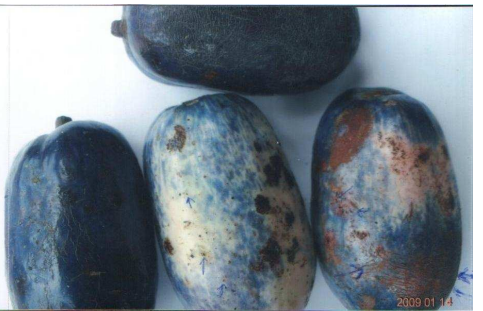

(f)

Fig. 4: The spots marked by arrows are cell surface receptors while the grooves marked by arrows are cell surface receptor channels

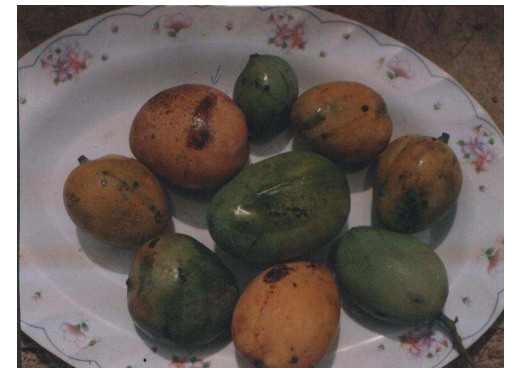

(a)

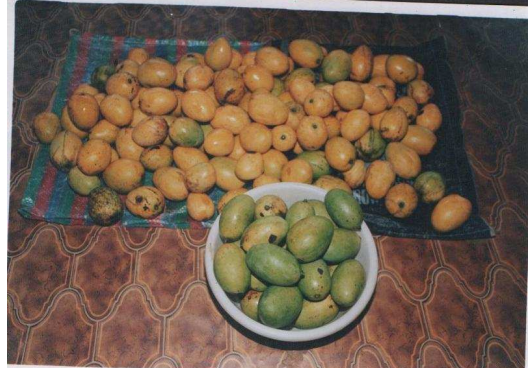

(b)

Fig. 5: The spots marked by arrows are cell surface receptors while the grooves marked by arrows are cell surface receptor channels

Commentary on the figure: The single spots, dots or depressions on the human skin; on the oranges; on the persea spp and on the mango fruits are the sites of cell surface receptors. All the samples shown in all the figures show that infective pathogens infect the human or plant body through attachment to these cell surface receptors. They also show that the cell surface receptors are arranged in straight lines which criss-cross the organ in different directions. The pictures also show that the cell surface receptors are interconnected by channels. The self-applied gummy, shinny substance along the infected receptor channels of the persea spp fruits and on the infeted mango spp. Fruits in Fig.re 5a shows that living organisms produce an endogenous substance that mediates infective organism killing and body healing. The rashes or raised spots on the cell surface receptors of the Candida infected site of the human thigh shown in Fig. 1a show that the human body has an indeginous mediator of infective organism killing and body defence/protection. The glossy shining of the surface of the healthy mangoes in Fig. 5b (just like the infected mango fruit parts to which the endogenous healing medicine had been applied) shows that the endogenous mediator of the mango's body defence is always applied to the whole body to protect. Thus the endogenous mediator of body's defence in living things is also the mediator of normal body physiological functioning of that organism.

\section{DISCUSSION}

These results of this study show that oral and topical $V$. amygdalina leaf extract and leaf powder have Candida species killing and elimination properties. 
These actions of $V$. amygdalina leaf extract demonstrated its anti-oxidant properties which has been demonstrated in many studies (Siamba et al., 2007; Suzui et al., 2006; Otogawa et al., 2007).

In the second part of the study results obtained from the examination of the procedures and patterns of disease infectivity in human and plant parts showed that disease infective organisms achieve infection of the body by attaching themselves to cell surface receptors and their interconnecting channels. Disease infective organisms establish themselves by growing and flourishing along the receptor channels of cell surface receptors they have successfully attached themselves to until they destroy these receptors and channels. Destruction of all the cell surface receptors and their channels results in the death or annihilation of the host organism.

The findings of this study also showed that living organisms have a main endogenous substance that mediates both their body's defence and their normal physiological functioning which is therefore the owner of the cell surface receptor. Other endogenous substances which participate in normal body functioning or body's defence or offence interact with the body through the receptor of the main mediator of the body's defence and normal functioning, the cell surface receptor. Exogenous substances like drugs, toxins, venoms et cetera attack or defend the body through interacting with the receptor of the host body's defender.

IT follows from the findings of this study that drugs like plant extracts [like Carica papaya extract which contains retinoids] are themselves the endogenous defence substances of their own organism and they defend the human or other organism's body from disease infection and disorder just as they protect their own organism (Guruswamy and Benbrook, 2006; Holmes et al., 2004; Benbrook et al., 1997; Chiu et al., 2006). The structure of such benevolent substances would therefore resemble those of a host organism's defence mediator. The body defence substances of malevolent organisms would fit into the receptor of the body defence mediator of their enemy or prey but their structure would be such that they would block the cell surface receptors of their enemy organism and thus inhibit the mediation of normal body functioning and body's defence by the legitimate owner of the cell surface receptors. This is how predators kill their prey. It is also how poisonous snake venom kills I human victim. Substances like lidocaine (an anesthetic); tetrodotoxin and afflatoxin therefore inhibit or antagonize the normal functioning of the body by blocking the excitatory actions of the mediator of normal body functioning.

\section{CONCLUSION}

This study concludes that the cell surface receptor of living organisms are the sites through which infective pathogens attach to and enter their body and the channels which connect the cell surface receptors are destroyed by disease.

Since this study has shown that the cell surface receptor of humans has two receptor heads, endogenous and exogenous substances interact with the cell surface receptor through one or both of these receptor heads or ends of the cell surface receptor. The study which showed that Ral-binding protein is required for the maturation and function of dendritic cells (Borvak et al., 2010) confirms the involvement of cell surface receptors (cell protein) and the body endogenous substance whose receptor it is, in maintenance of normal body functioning.

\section{REFERENCES}

Benbrook, D.M., M.M. Madler, L.W. Spruce, P.J. Birckbichler and E.C. Nelson et al., 1997. Biologically active heteroarotinoids exhibiting anticancer activity and decreased toxicity. J. Med. Chem., 40: 3567-3583. PMID: 9357524

Borvak, J., M. Sahu, V. Joy, J. Singhal and S. Yadav et $a l ., 2010$. Ral-binding protein is required for the maturation and function of dendritic cells. Am. J. Immunol., $\quad 6$ : $29-42$. 10.3844/ajisp.2010.29.42

Chiu, P.M., H.C. Feng, D.M. Benbrook, H.Y.S. Ngan and U.S. Khoo et al., 2006. Effect of all-trans retinoic acid on tissue dynamics of choriocarcinoma cell lines: An organotypic model. J. Clin. Pathol., 59: 845-850. PMID: 16461808

Guruswamy, S. and D.M. Benbrook, 2006. Retinoids chemosensitize ovarian cancer cell lines to cisplatin independent of nuclear receptors and p53. Am. J. Pharmacol. Toxicol., 1: 87-93. DOI: 10.3844/ajptsp.2006.87.93

Holmes, W.F., D.R. Soprano and K.J. Soprano, 2004. Synthetic retinoids as inducers of apoptosis in ovarian carcinoma cell lines. J. Cell. Physiol., 199: 317-329. PMID: 15095280

Otogawa, K., K. Kinoshita, H. Fuji, M. Sakabe and R. Shiga et al., 2007. Erythrophagocytosis by liver macrophages (Kupffer cells) promotes oxidative stress, inflammation, and fibrosis in a rabbit model of steatohepatitis: Implications for the pathogenesis of human nonalcoholic steatohepatitis. Am. J. Pathol., 170: 967-980. PMID: 17322381 
OnLine J. Biol. Sci., 11 (2): 76-83, 2011

Suzui, M., N. Sunagawa, I. Chiba, H. Moriwaki and N. Yoshimi, 2006. Acyclic retinoid, a novel synthetic retinoid, induces growth inhibition, apoptosis, and changes in mRNA expression of cell cycle- and differentiation-related molecules in human colon carcinoma cells. Int. J. Oncol., 28: 1193-1199. PMID: 16596235
Siamba, D.N., L.O. Okitoi, M.K. Watai, A.M. Wachira and F.B. Lukibisi et al., 2007. Efficacy of Tephrosia vogelli and Vernonia amygdalina as anthelmintics against Ascaridia galli in indigenous chicken. Lifestock Res. Rural Dev., 19. 